\title{
SOBRE LA CREACIÓN POÉTICA BECQUERIANA
}

Lin el mes de marzo de 1936 , el número 3 de Floresha de prosa y verso (Madrid, Imprenta Anaya) ' publicó como encarte la fotocopia de un manuscrito autógrafo y firmado de Gustavo Adolfo Bécquer. Es una cuartilla muy irregular, que mide $22 \times 16$ cms. $y$ tiene varios orificios o roturas y señales profundas de doblado. Fue entregado en febrero de 1892 al pintor Rafael Romero Barros, entonces director del MIuseo de Bellas Artes de Córdoba ${ }^{2}$ y antiguo condiscipulo de los hermanos Bécquer. Iil donante fue un hijo de Gustavo Adolfo, que pasaba por la capital cordobesa camino de Sevilla, en situación económica nuy apurada. Recibió largamente la hospitalidad de los cordobeses y ofreció el autógrafo de su padre, el pocta, escrito que aun hoy' se guarda en las vitrinas del Museo cordobés ${ }^{3}$.

Iil texto becqueriano es perfectamente legible y contiene los catorec renglones que siguen:
I. Dulce misica en mi oido (tachado)
2. Al necer las azules campanillas (tachado)
3. Hoy la tierra y / el mindo (tachado)
los cielos me somien

\begin{abstract}
1 Iil número 3 de Floresta -editado por un grupo de alumnos de la lacultad de liilosofía y Letras de Madrid - se publicó en homenaje a I3écquer, y reproducia, además del autógrafo que estudio, dos rimas de Gustavo y textos poéticos -en verso y en prosa- de M. Rubio Saura, I'rancisco Giner (director), ' 'aulino Garagorri, Iélix Utray, Juana Mendoza de Castro, Agustín Caballero, I, uis Delgado y Liduardo de la Iglesia.

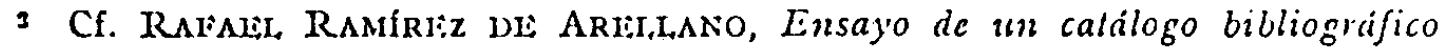
de escritores de Córdoba, Madrid, 1922-23, t. II, p. 157.

- Cf. R. G., El centenario de Bécquer, en Córdoba, de 9-XiII-Iglg. He de agradecer a mi docto anigo el catedrático cordobés don Juan Cómez Crespo una cxcelente fotografia del autógrafo becqueriano, y certeras noticias sobre él.
\end{abstract}




\author{
fondo \\ 4. hoy llega al / centro (tachado) de mi alma el sol. \\ 5. hoy la he visto, la he visto y me ha mirado \\ Hoy creo... en Dios. \\ 7. Como crece en el pdraino la flor (tachado) \\ 8. Al brotar de un reldmpago nacemos \\ $y$ ain brilla su fulgor cuando morimos \\ 10. $\quad$ tan corto es el vivir. \\ La gloria tras que corremos \\ sueños son al fin que perseguimos \\ 13. Desperlar es... morir \\ I4. G. A. Bticquzir (rubricado)
}

La letra y firma son incuestionablemente becquerianas; pero el autógrafo carece de consignación directa sobre-fecha, aunque del tema de los pasajes poéticos reunidos pueda indirectamente deducirse la época temprana de su composición.

La primera observación que puede hacerse sobre este valioso autógrafo cordobés es anotar la heterogénea varjedad del material recogido en el estrecho ámbito de una cuartilla, sin duda uno de aquellos papeles y tarjetas de visita que no tenían uso, en que según Ramón Rodríguez Correa transcribieron sus primeras creaciones literarias Gustavo Adolfo y Manuel Mirguía ${ }^{1}$.

Dos grupos podrían hacerse con los textos becquerianos recogidos en este autógrafo:

a) Los renglones sueltos $-\mathrm{y}$ tachados por Bécquer- que aparecen como meros núcleos de creación poemática (renglones $1,2 y$ 7).

b) I,os demás textos que aparecen constituyendo estrofas, aunque en distinto grado de construcción poética (renglones 3-6 y 8-13).

Iin el primero de estos grupos destaca el renglón 7 (como crece cn cl páramo la flor), que, pese a la vigorosa tachadura de Gustavo, pasó

- Cf. Prólogo de Agua pasada, Madrid, 1894, p. XIII. 
a ser el verso 8 -y la cumbre expresiva - de la rima $A$ Casta, inédita al fallecimiento de Bécquer, y sólo aparecida en la IV edición de sus Obras (Madrid, I885).

El texto de este poema becqueriano ${ }^{1}$, construido en presente todo él, y manifestativo de un vibrante enamoramiento, pudiera indicar que fue escrito en las semanas que corren entre 3 de abril de $186 \mathrm{I}$-en que se incoa el expediente matrimonial de Casta Esteban y Gustavo Adolfo- y el r9 de mayo siguiente en que se celebra el matrimonio, en la iglesia madrileña de San Sebastián ${ }^{2}$. Lin ese mismo tiempo se publica también la rima I2 (Por unu mirada, un mundo) ${ }^{3}$, igualmente inspirada por Casta. Con ello pudiera señalarse una primera indicación cronológica, en este autógrafo cordobés, tan carente de ellas. El renglón 7 hubo muy probablemente de escribirse antes de mayo de $\mathrm{r} 86 \mathrm{r}$, y los textos que le acompañan en la maltratada cuartilla autógrafa son seguramente de feclia análoga.

Parecida anotación puede formularse acerca del renglón 2 (Al mecer las oscuras campanillas), que, con la sola anteposición de un condicional si, se configuró como el primer endecasilabo de la rima I7. Liste poema se publicó en mayo de I866, en las páginas de El Museo Universal, cuando Gustavo Adolfo dirigió efectivamente la revista, y en el tiempo en que, según Narciso Campillo, la tranquilidad económica que suponía para Bécquer su cargo de fiscal de novelas, permitió al poeta preparar los textos de la colección que fue después Libro de los gorriones ${ }^{4}$. Bajo cl aspecto cronológico, este renglón 2 solanente atestigua que el autógrafo es anterior a mayo de 1866 , lo que indirectamente viene a corroborar el dato of recido por el renglón 7 .

'́ampoco el octosílabo recogido en el renglón I (Dulce misica en mi oído) aporta precisión alguna para datar este autógrafo becqueriano de Córdoba, porque no sirvió - que yo sepa- como núcleo germinal de ningún poema de Gustavo, pese a la indudable cercanía del tema musical a la vivencia creadora de Bécquer, bien dotado para la audición melódica y discreto ejecutante ${ }^{5}$.

1 Para el texto y numeración de las Rimas sigo la edición Rimas y prosas, de RATAIi, di: Baibin y ANTonio Roldín, Madrid, 1968.

2 CF. R. DE BAIbfN, Doctumentos becquerianos, en Revista de Bibliografia Nacional, Madrid, 1944, pp. 8-18.

- Cf. R. DE Burbín, Sobre la Rima XXIII de G. A. Bécquer, Homenaje al profesor Alarcos, t. II, Valladolid, I960.

- Cf. N. Canmin,o, G. A. Bécquer, en Paginas desconocidas de Guslavo Adolfo Bécquer, cd. de IF. Icimisias Iíminon, t. I, Madrid, I923, pp. 22-23.

- Cf. 2i. Gutrikri:z Ganuko, Mis primeros ochenla años, MIadrid, i925. pp. $197-98$. 
En el segundo grupo de los textos consignados en el autógrafo entregado a Romero Barros, los renglones 8- $\mathrm{r} 3$ transcriben una versión poemática de la rima 86 , que también fue publicada por El Musco Universal, en septiembre de 1866 . $Y$ es de notar que la primera semiestrofa de esta rima apareció tal como la recoge el autógrafo de Córdoba:

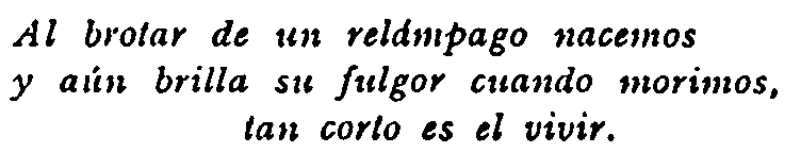

Más tarde la paciente y perfectiva insistencia de Gustavo, sobre sus textos poemáticos, escribió en el Libro de los gorriones la que fue forma definitiva,

\section{Al brillar de un reldmpago nacemos $y$ aún dura sil fulgor cuando morimos}

En cuanto a la segunda semiestrofa de esta rima 86 , el proceso de su revisión y modificaciones fue más inmediato y amplio. El ritmo métrico de los renglones II-I 2 resulta enteramente desajustado dentro del ámbito de la estrofa yámbica en que encuadra la totalidad del poema ${ }^{1}$. Así el renglón II (La gloria tras que corremos) constituye un claro octosílabo con acentos en los tiempos métricos $2 .^{\circ}$ y $7 .^{\circ}$, en tanto que el renglón I2 (sucños son al fin que perseguimos) es un indudable decasílabo con acentos de localización impar o trocaica en $\mathrm{I} .^{\circ}, 3 .^{\circ}, 5 .^{\circ}$ y $9 .^{\circ}$ tiempos métricos. Esta hibridación y mezcla de ritmos en la estrofa binaria $^{2}$ no se da en Bécquer, que, por su formación literaria y por su aguda sensibilidad acústica, usó en sus poemas, con absoluto predominio, la eufonía de los metros armónicos. Quizá por ello al publicar esta rima 86 -bosquejada en los renglones 8-13-Gustavo restablece la congruencia ritmica de la segunda semiestrofa, y redacta el contenido de los renglones I I-I2, dándoles una nueva versión.

La gloria y el amor tras que corremos sombras son de un sueño que perseguimos...

Aquí el poeta ha dado a los mismos versos entera simetria, sobre un esquema endecasilíbico, y ha configurado su acentuación dentro del

1 Cf. R. DIE BAIníN, Sisfema de rllmica castcllana, Madrid, 1968, VIII, 3-4

2 Cf. Idem, VIII, I-2. 
ritmo yámbico, que en el primero de los versos nuevamente redactados marca acento en $2 .^{a}, 6 .{ }^{a}$ y $10 .^{a}$ silabas métricas; en el segundo de los grupos melódicos reliechos, en $1 .^{\circ}, 4 .^{\circ}, 6 .^{\circ}$ y $10.0^{\circ}$ tiempos. El texto de lo que después fue rima 86 , parece haber sido renovado fundamentalmente por exigencias de armonía rítmica, annque la inclusión del amor entre las sombras dc un sueño pudiera bien obedecer - además de a un aumento de los tiempos métricos- al áspero y hondo desengaño amororo que sufre Gustavo Adolfo en el tránsito de los años I 860 al ISGI ${ }^{1}$.

\section{IV}

De índole distinta es la motivación que parece justificar los cambios que se anotan en los renglones 3-6. Los versos que transcribe esta parte del autógrafo becqueriano quedaron inéditos a la muerte de Gustavo, y tanto en el Libro de los gorriones como en las Obras constituyen el texto de la rima 29. Son tres endecasilabos que cierran una estrof tetraversal con un pentasilabo agudo, $y$ las variantes de los renglones 3-4 en nada afectan ni a la canticlad ni a la acentuación del conjunto estrófico.

En el renglón 3, Gustavo Adolfo vacila al plasmar la fórmula poemática con que significa la total plenitud del universo creado, y prueba cambiar el doble sujeto oracional la ticrra y los ciclos por el binomio enumerativo la tierra y el mundo. Pero termina - como lo muestra el tachado- por eliminar el término mundo, sin duda al observar que este sustantivo viene a duplicar el significado de licrra, sin llegar a ser un verdadero pleonasmo expresivo. Parece también visible que la construcción intentada mutilaba además el magno vuelo imaginativo de la enumeración la ticrra y los ciclos. Esta variante estilística significó en Bécquer la preferencia - más o menos consciente - del poeta por la fórmula genesiaca para significar la plenitud cósmica, sobre los términos elegidos por la tradición grecolatina para significar conceptos análogos ${ }^{2}$.

Como ello sea, la fórmula la tierra y el cielo prevaleció en la concepción poética de Gustavo Adolfo como definitiva. Debió de serle singularmente grata, porque la consigna también en la rima 23:

\section{Los ojos entreabre, aquellos ojos \\ tan claros como el dia,}

y la tierra y el cielo, chanto abarcan

arden con nueva luz en sus pupilas ${ }^{3}$.

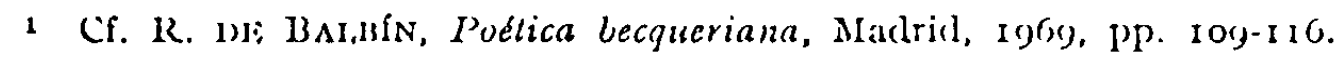

2 Cf. II. Zimmirkinan, Los mélodos hislórico-crfticos en el N'uezo Testamento. Madrid, ro69, pp. 8-9.

3 Cf. G. A. BícQuik, Rimas y prosas, p. 47. 
Para indicar la plenitud del arte poético creador, Gustavo vuelve a unir -aunque en distinto orden- ambos términos en la rima 5:

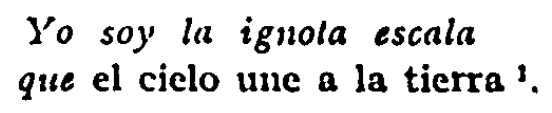

Este tópico expresivo - la ticrra y los ciclos-, pese a su indudable ascendencia genesiaca, no parece proceder directamente del texto biblico, ya que, en la versión de la Vulgata, el primer versículo del Génesis da otro orden en la enumeración (In principio creavit Dens caelumn et terrain) ${ }^{2}$. Tampoco se recoge la configuración becqueriana en el texto latino del padrenuestro (Fiat voluntas tula, sicul in coelo et in terra, Mit. 6,10$)^{3}$. Es muy probablemente -dado el neto popularísimo de la creación poética becqueriana- origen de la fórmula enumerativa el texto catequístico y popular del padrenuestro, tal como se recoge y se incorpora a la recitación descle finales del siglo xvi hasta nuestros días 4.

'También en el renglón 4 se puede anotar una variante recogida tan solo -que sepamos- en el autógrafo cordobés de Romero Barros. Aunque tachado, se lee enteramente el sustantivo cenlro como escrita primeramente entre los vocablos al y de. Esta palabra centro, con su complemento de mi alma, responde en algún modo a la técnica terminológica de la mística, y la locución cenlro del alma sirvió entre los autores ascéticos y místicos españoles para la designación de la hondura esencial del espíritu ${ }^{5}$. Eil carácter abstracto y preciso de este vocablo técnico llevó a Bécquer - sin duda - a buscar un vocablo bisílabo grave con que reemplazar, dentro del verso endecasilabo, el tecnicismo centro; y para ello sobreescribe la voz fondo, lexema de más amplia polisemia y de grande capacidad evocativa. Pero esta potenciación poética del rcnglón 4 no aparta a Gustavo de las fuentes de su léxico; el término fondo es también de uso frecuente entre los tratadistas clásicos para significar la intimidad del alma, y especialmente lo emplea San Juan de la Cruz en la Llama de amor viva. Dice declarando el verso 3 de la

Cf. Idem, p. 34 .

2 Cf. Biblia Sacra iuxta vulgatam clementinam, ed. A. ColungA et L. TURRADO, Madrid, MCIXI,VI, p. 3.

3 Cf. Idem, p. 1.277. Sagrada Biblia traducida de la Vulgala Latina, por don FeidPE Scfo de SAN Miculer, Madrid, 1855, t. III, p. I 2.

- Cf. Ji:kúnimo RUPsi,DA, de la Compañía de Jesús, Doctrina Cristiana con una Exposición breve, ed. José BRavo Ugarte, S. J. según la principe de Philippe de Juntn, Burgos, 159) , p. 38.

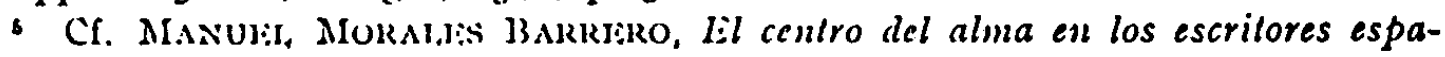
ñoles del Siglo de Oro, Madrid, I968, pp. 4-I 4 y 43-53. 
Canción I: "Su negocio es ya solo recibir de Dios, el cual solo puede en el fondo del alma... hacer obra y mover el alma cn clla" ${ }^{1}$. I más adelante, en la introducción del comentario a la Canción IV, enlaza y une los dos vocablos usados por IBécquer, y viene a testimoniar la estrecha sinonimia que se da entre ellos, al escribir: "El recuerdo que haces, oh Verbo Esposo, en cl centro y fondo del alma, que es la pura e intima substancia de clla..." ${ }^{2}$

La expresión fondo del alma es usada por Gustavo Adolfo en otros dos poemas. Así en la rima 7, en cuya tercera estrofa se lee:

$$
\begin{aligned}
& \text { Ay - pensé-; cranlas veces el genio } \\
& \text { asi ducrme en el fondo del alma... }
\end{aligned}
$$

La locución aparece también en la rima IS, con una leve matización

$$
\begin{aligned}
& \text { Cuando entre la sombra oscura } \\
& \text { pcrdida una voz murmura } \\
& \text { turbando su triste calma. } \\
& \text { si en cl fondo de mi alma } \\
& \text { la oigo dulce resonar... }
\end{aligned}
$$

Y cabe hacer la anotación de que se trata en todos los casos de poemas de amor alegre o visión esperanzada de la vida.

En cuanto a la rima 29, también la hermosa metáfora del renglón 4 (Hoy llcga al fondo de mi alma el sol), parece encontrar antecedentes en San Juan de la Cruz. Dice el místico en la declaración de la Llana de annor viva (Canción II, v. I): "No os maravilléis de que Dios llegue a algunas almas allamente hasta aqui, pues el sol se singulariza en hacer algunos afectos maravillosos.... Y en el comentario del Cánlico espirilual, escribe (Canciones XX y XXI, v. I4): "Pues si quisiéramos hablar de la iluminación de gloria que en este ordinario abrazo que tiene dado el alma, algunas veces hace con ella... a manera del sol cuando de lleno embiste li mar, esclarece hasta los profundos senos $y$ las cavernas.... ${ }^{3}$

1 Cf. SAN JUAN de la CRUz, Obras, Madrid, 195S, p. 827.

2 Cf. Iden, p. 930.

3 Cf. Idem, pp. 852 y 69 r. No es ésta la inica locución procedente de los místicos que pasó al vocabulario becqueriano. Iil sintagma noche del alma, aparece ell la rima 2:

X'o sé un limno gigante y extraño que anuncia en la noche del alma una aurora...

$Y$ con más estricta matización significativa se consigna en la segunda estrofa de la rima 50 - publicada ya en 186 i en el Correo de la Moda:

La brilladora luz es la alegría:

la icnladora sombra es el pesar;

iay! ¿ch la oscura noche de mi ahma, cuánlo amanccerí? 
La creación poética de Bécquer y sus modos de realizarse reciben, en este autógrafo cordobés de Romero Barros, algunas precisiones que podrian deducirse de la extraordinaria variedad de los textos transcritos.

En cuanto al acto poético creador, es notable la pluralidad de las vivencias que coexisten simultáneamente. Junto al afecto amoroso alegre expresado en los renglones 3-6 - rima 29- y en el renglón 2 -rima 17 - recoge Gustavo Adolfo el sentimiento de melancolía y desaliento que inspira el renglón 7 -rima $A$ Casta-y el ascético desencanto de la vida que, con acentos calderonianos, nutre los renglones 8-I3 - rima 89-. Parecen, según estos datos, convivir a un mismo tiempo en el alma de Gustavo vivencias diversísimas que - cuando menostuvieron, en el espiritu del poeta y en una misma fecha, el estínulo creador suficiente para animar la imaginación y la pluma de Gustavo Adolfo. Quizás esta observación obvia pudiera ser anotada como advertencia contra la tentación crítica de establecer una cronología de la obra becqueriana, fundada exclusivamente en la diferenciación temática, considerada como huella de ura trayectoria vital.

Por lo que se refiere a los modos de configurar el signo poético, puede apuntarse también una flexible variedad. Los renglones $I, 2 y 7$ documentan un proceso fragmentario y lento en la composición del pocma, que comienza por una anotación germinal y primaria, y más tarde puede desenvolverse hasta constituir unidad poemática conpleta. Sin que ésta resulte, sin embargo, etapa mecánica y fatal, como lo muestra el renglón I (Dulce música en mi oído), octosílabo enteramente construido que no llegó - que sepamos- a cuajar en la creación de un poema. Los otros dos renglones aislados que recoge el autógrafo cordobés, sí llegaron a constituir un tono poemático, aunque en forma visiblemente distinta. Lil renglón 2 (Al mecer las azules campanillas) vino a ser el verso inicial - y como arranque y módulo- de la rima $\mathrm{I}$; mientras que, inversamente, el renglón 7 (como crece en el páramo la flor) fue la culminación, remate y término de la rima $A$ Casia, y resultó en alguna manera resumen de todo el poema.

En cambio, el segundo grupo de los textos que aquí estudio parece atestiguar una creación pocmática más acabada y completa, que recoge en los renglones 8-13 un texto explícito y construido de la rima 86. 'Tampoco en estos casos la fantasla y el quehacer poético de Gustavo Adolfo se da por satisfecho $y$ pasa definitivamente del acto poético al signo 
poemático. Aquella dificultad que tanto ponderó el poeta para hallar la expresión poética total de la idea poética sigue estimulando la actividad creadora de Bécquer, que aun en el Libro de los gorriones - para los años I 868 y I 870 - insiste en perfilar la configuración de unos poemas que llegan a alcanzar su plenitud expresiva en la flexible sencillez y espontaneidad.

Podría, por último, apuntarse que las variantes registradas en el autógrafo Romero Barros vienen a documentar una profunda raíz de la creación poética becqueriana, no siempre anotada. Entre las atentas lecturas que con los años vinieron a enriquecer el talento poético -original y renovador- de Gustavo Adolfo Bécquer, parece indudable haya que contar con la veta entrañada y profunda de los escritores místicos españoles y muy señaladamente con el directo influjo de San Juan de la Cruz ${ }^{1}$.

\section{RAIALL DE BALBÍN}

1 Iistos contactos de liécquer con los ascéticos y místicos del Siglo de Oro español fueron ya finamente atisbados por el P. IRANCisco BLANCO García, en La Literatura española del siglo $X I X$, Madricl, 1910, t. II, p. 82, cuando escribe refiriéndose a los precedentes de la inspiración becqueriana: "si el subjetivismo lirico ha hecho alguna vez forluna entre nosotros, no es sino en los poetas místicos. como San Juan de la Cruz y Fr. Luis de León, donde deben buscarse sus huellas. 